\title{
Solving Multi-Response Problem Using Goal Programming Approach and Quantile Regression
}

\author{
Sara Abdel Baset ${ }^{1, *}$, Ramadan Hamed ${ }^{2}$, Maha El-Ashram², Zakaria Abdel Samea ${ }^{2}$ \\ ${ }^{1}$ Department of Economics, Faculty of Management Science, October University for Modern Sciences \& Arts, Giza, Egypt \\ ${ }^{2}$ Department of Statistics, Faculty of Economics and Political sciences, Cairo University, Cairo, Egypt
}

Received October 19, 2021; Revised January 2, 2022; Accepted January 17, 2022

\section{Cite This Paper in the following Citation Styles}

(a): [1] Sara Abdel Baset, Ramadan Hamed, Maha El-Ashram, Zakaria Abdel Samea, "Solving Multi-Response Problem Using Goal Programming Approach and Quantile Regression," Mathematics and Statistics, Vol. 10, No. 1, pp. 201 - 214, 2022. DOI: 10.13189/ms.2022.100119.

(b): Sara Abdel Baset, Ramadan Hamed, Maha El-Ashram, Zakaria Abdel Samea (2022). Solving Multi-Response Problem Using Goal Programming Approach and Quantile Regression. Mathematics and Statistics, 10(1), 201 - 214. DOI: $10.13189 / \mathrm{ms} .2022 .100119$.

Copyright $\odot 2022$ by authors, all rights reserved. Authors agree that this article remains permanently open access under the terms of the Creative Commons Attribution License 4.0 International License

\begin{abstract}
Response surface methodology (RSM) is a group of mathematical and statistical techniques helpful for improving, developing and optimizing processes. It also has important uses in the design, development and formulation of new products. Moreover, it has a great help in the enhancement of existing products. (RSM) is a method used to discover response functions, which meet and fulfill all quality diagnostics simultaneously. Most applications have more than one response; the main problem is multi-response optimization (MRO). The classical methods used to solve the Multi-Response Optimization problem do not guarantee optimal designs and solutions. Besides, they take a long time and depend on the researcher's judgment. Therefore, some researchers used a Goal Programming-based method; however, they still do not guarantee an optimal solution. This study aims to form a goal programming model derived from a chance constrained approach using quantile regression to deal with outliers not normal and errors. It describes the relationship between responses and control variables at distinctive points in the response conditional distribution; it also considers the uncertainty problem and presents an illustrative example and simulation study for the suggested model.
\end{abstract}

Keywords Goal Programming (GP), Quantile Regression, Multi Response Optimization (MRO), Chance Constrained

\section{Introduction}

One of the main objectives to attain a quality distinctively is specifying the appropriate operating condition. However, the majority of industrial applications have more than one response, and the investigator seeks operating functions that serve all quality characteristics simultaneously.

In real applications, multiple responses are observed. So, there is a need to reach some type of compromise about optimum conditions that are examined. The methodology becomes more difficult as the number of responses and factors become larger.

Response surface methodology (RSM) is a mixture of mathematical and statistical ways that can be used for optimizing, improving and developing methods.

RSM is applied in the new formulation of products and advancement of design too. Moreover, it has a contribution to the existing product designs improvement as defined by Myers and Montgomery [1].

The following section shows that all the classical methods of (MRO) do not guarantee an optimal design or optimum solution. Furthermore, it takes a long time and depends on a researcher's judgment. Therefore, some researchers used a Goal Programming method to solve this problem, yet it does not guarantee an optimal solution because it doesn't consider the randomness in MRO.

This paper tries to present (MRO) methods and main concepts. In addition, it aims at constructing a mathematical programming model based on a chance 
constrained approach: to deal with randomness in the multi-response optimization problem (MRO) and to get the best design and optimum solution considering the response variable and decision variables directly.

This paper includes five more sections besides the introduction section. The second section presents the literature review; section three shows the suggested model; section four clarifies an illustrative example for the use and results of the suggested model; section five presents a simulation study to check the performance of the suggested model and the last section presents the discussion and conclusion for the suggested model.

\section{Literature Review}

This section clarifies the MRO concept and problem as it introduces the main classical methods presented for it. Moreover, it presents two of the latest and important previous studies that used Goal programming to solve MRO.

\subsection{The Multi Response Optimization Problem (MRO)}

Montgomery [2] defined RSM as a mixed method that is used for the modeling and analysis of cases where a studied response is affected by several variables while the aim is response optimization.

A response variable: $y$

Independent variables: $x_{1}, \ldots \ldots, x_{k}$

Model: $\mathrm{y}=\mathrm{g}\left(\mathrm{x}_{1}, \ldots, \mathrm{x}_{\mathrm{k}}\right)+\varepsilon$

RS model: $\mathrm{y}=\mathrm{f}\left(\mathrm{x}_{1}, \ldots, \mathrm{x}_{\mathrm{k}}\right)+\varepsilon f$ is usually 1 -st or 2 -nd order polynomial.

The goal here is to guide the experimenter efficiently along a trail of improvement toward the general matter of the optimum. Based on this model Montgomery [2] represented a graphical solution.

\subsection{Classical Methods}

Ding, Lin and Wej [3] proposed the first method to solve the multi-response problem. They presented the dual response optimization (DRO) method, yet they mentioned that (DRO) are robust design techniques and they might not be appropriate if there is more than one response of interest. Najafi, Salmasnia, and Kazemezaheh [4] also presented the DRO method; they modeled variance and mean of the single response, respectively. Such methods try to adjust control variables where the targeted response is as near as possible to its target value under low sensitivity to uncontrollable variables.

Najafi, Salmasnia, and Kazemezaheh [4] classified MRO methods into three main categories as follows:

(1) The first category: is working great when there is a small number of control variables. This method includes covering each response contour plot and discovering the interesting region that satisfies all the responses. However, for more than three responses, covering contour plots becomes inappropriate, which represents the disadvantage of this category.

(2) The second category: is choosing one response variable as the main objective function; and optimizing it is achieved by adding other response variables in the rules of the constraint. The main disadvantage of these methods is that they do not consider the importance of all the response variables. Besides, it is not easy to select the primary response variable as an objective function.

(3) The third category: is aggregating the multi responses in one single function, and one objective function problem is satisfied.

\subsection{Goal Programming for the Multi-Response Optimization Problem}

Kazemzaded et al., [5] proposed a form of the loss function and the desirability method. The quadratic constraints forms and objective functions are coming after:

$$
\text { Min } N D_{\text {overall }}=g_{1}+g_{2}+g_{3}+g_{4}
$$

Subject to

$$
\begin{gathered}
\sum_{j=1}^{m} \gamma_{j}\left(1-d_{j}\right)^{2}-s_{1} g_{1}=T_{1} \\
\sum_{j=1}^{m} a_{j}\left(\frac{\sigma_{j}^{2}(x)}{y}\right)-s_{2} g_{2}=T_{2} \\
\sum_{j=1}^{m} b_{j}\left(\frac{\hat{\sigma}_{j}^{2}(x)}{y}\right)-s_{3} g_{3}=T_{3} \\
c_{p r}\left(1-d_{p r}\right)^{2}-s_{4} g_{4}=T_{4} \\
x \in \Omega \text { and } y=\max \left(\hat{\sigma}_{j}^{2}(x)\right)
\end{gathered}
$$

Where $\mathrm{j}=1,2, \ldots, \mathrm{m}$ which is the number of responses and $\gamma_{j}$ is the jth response weight that the customer can decide.

The estimated $\hat{y}(\mathrm{x})$ can be transformed by the desirability function approach to a free value scale called the desirability $d_{j}$ which is the value for such responses $s_{k}$ and $T_{k}$. where $s_{k}, T_{k} ;(k=1,2,3,4)$ are weights and targets defined by users, respectively. $\sigma_{j}^{2}(x)$ is the variance of observed values of the $\mathrm{j}^{\text {th }}$ response at the setting of $\mathrm{x}=\left(\mathrm{x}_{1}, \mathrm{x}_{2}, \ldots, \mathrm{x}_{\mathrm{n}}\right)^{\prime}$ as a decision variable; $\hat{\sigma}_{j}^{2}(x)$ is the variance for this response at $\mathrm{x} ; \Omega$ is the spherical or rectangular experimental region and $\mathrm{ND}_{\text {OVERALL }}$ is the non-desirability of all factors: $\mathrm{g}_{1}$ is for bias; $\mathrm{g}_{2}$ is for variation; $g_{3}$ is for error and $g_{4}$ is for specification region.

As $d_{p r}$ is another desirability function for the probability of meeting, the response specifications and $c_{p r}$ are the weight of related desirability.

Moreover, the first and last constraints (2), (5) can be merged in one constraint as follows:

$$
\begin{gathered}
\sum_{j=1}^{m+1} \gamma_{j}\left(1-d_{j}\right)^{2}-s_{1} g_{1}=T_{1} \\
\text { Where } \gamma_{m+1}=c_{p r} \\
x \in \Omega
\end{gathered}
$$

This form is a combination of desirability function and 
loss function. There are four terms $\left(g_{1}, g_{2}, g_{3}\right.$, and $\left.g_{4}\right)$ in this equation which is non-desirability of bias, variation, errors of predictions and separation from responses' specification region. The loss function (eq.1) is adding the variance-covariance structure of the responses; the desirability function (eq.2) is that the desirability value uses scale-free and same magnitude of each response.

This model's problem is the sensitivity of setting variables ( $\mathrm{x}$ ) and $\mathrm{T}_{\mathrm{k}}$ conditions as they must be determined by the decision-maker, which affects the optimal solution.

\subsection{Optimization of Probabilistic Multi Responses Surface}

Hejazi et al. [6] presented the following model to ensure robustness in the results of modeling and optimization of multi-response surfaces with probabilistic coefficients and responses weights.

MRO problem is defined as follows:

$$
\begin{gathered}
\operatorname{Min} \hat{R}(X)=\operatorname{Min}\left(\begin{array}{c}
\hat{R}_{1}(X) \\
\hat{R}_{2}(X) \\
\cdot \\
\cdot \\
\cdot \\
\hat{R}_{p}(X)
\end{array}\right) \\
\operatorname{Min} \hat{R}(X)=\operatorname{Min}\left(\hat{R}_{1}(X) \hat{R}_{2}(X) \ldots \ldots \hat{R}_{P}(X)\right)
\end{gathered}
$$

Subject to

$$
L<X<U
$$

$$
\text { Where } l_{i}<x_{i}<u_{i}, \mathrm{i}=1,2, \ldots, \mathrm{n}
$$

Which is a nonlinear multi-objective optimization problem.

\section{Stochastic optimization problem:}

$$
\operatorname{Min}_{X} F(X)=\operatorname{Min}_{X} \sum_{k=1}^{p} w_{k}\left(d_{k}+\dot{d}_{k}\right)
$$

Subject to

$$
\begin{gathered}
\hat{R}_{k}(X)+d_{k}-\dot{d}_{k}=t_{k} \\
L<X<U
\end{gathered}
$$

Where

$$
\begin{gathered}
d_{k}=\frac{1}{2}\left(\left|\hat{R}_{k}(X)-t_{k}\right|+\left(\hat{R}_{k}(X)-t_{k}\right)\right) \\
\dot{d}_{k}=\frac{1}{2}\left(\left|\widehat{\mathrm{R}}_{\mathrm{k}}(\mathrm{X})-\mathrm{t}_{\mathrm{k}}\right|-\left(\widehat{\mathrm{R}}_{\mathrm{k}}(\mathrm{X})-\mathrm{t}_{\mathrm{k}}\right)\right) \\
W \in \Omega_{w}
\end{gathered}
$$

Where $\mathrm{W}$ is the response weight that belongs to response variables regions $\Omega_{w}$. Moreover, $\mathrm{w}_{\mathrm{k}}$. is the $\mathrm{k}^{\text {th }}$ response weight; $t_{k}$ is the target value and $R_{k}(x)$ is the predictor response.

Consider a multi-response model with functions $\hat{R}_{k}(x)$ of the form second-order polynomial function, $\mathrm{k}=1,2, \ldots, \mathrm{p}$.

$$
\begin{gathered}
\hat{R}_{k}(x)= \\
\hat{\beta}_{0 k}+\sum_{i=1}^{n} \hat{\beta}_{i k} x_{i}+\sum_{i=1}^{n} \hat{\beta}_{i i k} x_{i}^{2}+\sum_{i=1}^{n} \sum_{j>i}^{n} \hat{\beta}_{i j k} x_{i} x_{j}= \\
\dot{z}(x) \hat{\beta}_{k} \forall k=1,2, \ldots \ldots, p .
\end{gathered}
$$

Where $\operatorname{Var}\left(\hat{R}_{k}(X)+d_{k}-\dot{d}_{k}\right)=0$ assuming that $\mathrm{w}$ is a vector of independent random response weights. This model has considered multiple correlated response surfaces with stochastic nature where the weight and regression coefficients have been considered in probabilistic terms.

\section{The Proposed Model}

One of the main and basic mathematical programming methods to solve optimization problems is the Goal Programming approach (GP) which can deal with restricted problems with different constraints. GP works to simplify the constraints and treats it as a goal to be achieved by adding terms like positive and/or negative deviational variables to the objective function as cited in Rabee et al. [7].

The chance-constrained approach is one approach of the stochastic programming approaches that can be solved by using probabilistic programming, where the constraint(s) must be satisfied with a certain probability as defined by Armstrong and Balintfy [8]. The disjoint constrained treatment is considered in this study.

In the following part, the chance-constrained approach will be introduced.

$\mathrm{Yu}, \mathrm{Lu} \&$ Stander [9] mentioned that regression is used to check the relationship between some covariates and a response variable; it was considered one of the important methods for applying research for many years. Least squares regression for a response $\mathrm{Y}$ and a predictor $\mathrm{X}$ model the conditional mean, but it does not capture the conditional variance.

Rodriguez and Yao [10] mentioned that quantile regression can be used when the data collection could be of a big size; this leads to a large scale of datasets that cannot be fit into memory or multiple input variables. Besides, it is more robust to outliers and semi-parametric as it avoids assumptions about the error process parametric distribution. It is a powerful tool to detect the heterogeneous impact of covariates at various quantiles of the outcome and supplements excellently the mean regression when data includes outliers and long tails.

\subsection{The Proposed Chance Constrained Model to (MRO)}

This model is a modification of the stochastic optimization model in section (1.3). The objective function in the chance-constrained model remains the same, and the constraints became in a form of chance-constrained where $t_{k}$ in equation (11) is random variables with known probability distribution function $\mathrm{F}_{k}($.$) .$ 


$$
\operatorname{Min}_{x} \mathrm{Z}(x)=\operatorname{Min}_{x} \sum_{i=1}^{k} w_{i}\left(n_{i}+p_{i}\right)
$$

Subject to

$$
\left[\hat{R}_{i}(x)+n_{i}-p_{i}\right]_{i} \leq F^{-1}\left(1-\propto_{i}\right)
$$

Where $\mathrm{i}=1,2, \ldots, \mathrm{p}$, and $\mathrm{l}<x<\mathrm{u}$

$$
\begin{aligned}
\mathrm{W} & \in \Omega_{w} \text { and } \operatorname{cov}(w)=\sum_{w} \\
n_{i} & =\frac{1}{2}\left(\left|\hat{R}_{i}(x)-F^{-1}\left(1-\propto_{i}\right)\right|+\right. \\
& \left.+\left(\hat{R}_{i}(x)-F^{-1}\left(1-\propto_{i}\right)\right)\right) \\
p_{i} & =\frac{1}{2}\left(\left|\hat{R}_{i}(x)-F^{-1}\left(1-\propto_{i}\right)\right|-\right. \\
& \left.-\left(\hat{R}_{i}(x)-F^{-1}\left(1-\propto_{i}\right)\right)\right)
\end{aligned}
$$

Where the objective function $\mathrm{Z}(\mathrm{x})$ aims to minimize the summation of all deviations where $\mathrm{n}_{\mathrm{i}} \mathrm{s}$ are positive deviations, and $\mathrm{p}_{\mathrm{i}} \mathrm{s}$ are negative deviations.

Moreover, $\mathrm{w}_{\mathrm{i}}$ is the $\mathrm{i}^{\text {th }}$ response weight; $\hat{R}_{i}(x)$ is the predictor response, and $F^{-1}\left(1-\propto_{i}\right)$ is the inverse function of the target value $t_{k}$.

\subsection{Modified Quantile Regression Model}

Quantile Regression can be used to estimate $\hat{R}_{i}(x)$ to measure the variable effect of all individuals (not the average effect). It also helps in measuring heterogeneous effects of the variables which make quantile regression a more consistent approach than linear regression.

The Relation between the regressors and their outcome can be represented by the conditional function $Q_{q}(Y / X)$ where $\mathrm{q}$ is the quantile of an empirical distribution, $q \in(0,1)$.

$$
\begin{gathered}
F\left(Y_{q}\right)=q \text { and } Y_{q}=F^{-1}(q) . \\
\operatorname{Min~} \mathrm{z}=\sum_{j=1}^{q}\left[r_{j} \sum_{i=1}^{m} n_{i j}+\left(1-r_{j}\right) \sum_{i=1}^{m} p_{i j}\right]
\end{gathered}
$$

Subject to:

$$
\begin{gathered}
\sum_{i=1}^{m} b_{0}+x_{1 i} b_{1 j}+x_{2 i} b_{2 j}+x_{3 i} b_{3 j}+\cdots x_{k i} b_{k j}+n_{i j}- \\
p_{i j}=y_{i} \\
b_{10} \leq b_{20} \ldots \leq b_{q 0}, \\
b_{11} \leq b_{21} \ldots \leq b_{q 1}, \\
b_{1 k} \leq b_{2 k} \ldots . \leq b_{q k},
\end{gathered}
$$

Where $i=1,2,3, \ldots \ldots . m$. and $j=1, \ldots, q$.

Where $\mathrm{m}$ is the sample size; $\mathrm{k}$ is the number of independent variables; $r_{j}$ is the $\mathrm{j}^{\text {th }}$ quantile and $\mathrm{q}$ is the number of quantiles as n's are positive deviations and $p_{i} s$ are negative deviations. Constraint (21) aims to estimate bs $\left(b_{1 k}, b_{2 k}, \ldots, b_{q k}\right)$ over the required quantile and find the corresponding deviations. Moreover, the bs $\left(b_{1 k}, b_{2 k, \ldots .,} b_{q k}\right)$ increase as the quantile increases as shown in constraints $22-24$.

\section{Illustrative Example}

This section presents a simple numerical example to test the validity of the proposed model, evaluate its performance and results. Data used were about a real estate expert who needs to discover the relationship between various characteristics of houses and their sale prices. She collected data based on the following variables (as cited in Mann [11]).

Price (Y): the sale price of a house in thousands of dollars

Lot size $\left(\mathrm{X}_{1}\right)$ : the size of the lot in acres

Living area $\left(\mathrm{X}_{2}\right)$ : Living area in square feet

Age $\left(\mathrm{X}_{3}\right)$ : Age of a house in years

GAMS software was used to solve the modified model; to estimate the quantile regression using $25^{\text {th }}, 50^{\text {th }}$, and $75^{\text {th }}$ quantile and to minimize the distances $\mathrm{n}_{\mathrm{ij}}, \mathrm{p}_{\mathrm{ij}}$. The results showed zero non-optimal solution, zero infeasible solution and zero unbounded solutions. Also, table (1) shows results of the estimated B's, optimal solution and distances using the three quantiles.

$$
\begin{gathered}
\mathrm{y}_{0.25}=-17.382+11.404 \mathrm{x}_{1}+0.080 \mathrm{x}_{2}-0.699 \mathrm{x}_{3} \\
\mathrm{y}_{0.5}=-17.382+25.654 \mathrm{x}_{1}+0.080 \mathrm{x}_{2}-0.699 \mathrm{x}_{3} \\
\mathrm{y}_{0.75}=-17.382+28.939 \mathrm{x}_{1}+0.080 \mathrm{x}_{2}-0.484 \mathrm{x}_{3}
\end{gathered}
$$

Table (1) shows that the $B_{0}$ value doesn't change in the three cases (Figure 1) and $\mathrm{B}_{2}$ which measures the effect of living area changes doesn't change in the three cases (Figure 3). Moreover, $\mathrm{B}_{1}$ which measures the change in lot size increases with the increase of quantile (Figure 2), where the effect of age change on price (which is measured by $B_{3)}$ remains fixed in the first two cases $\left(25^{\text {th }}\right.$ and $50^{\text {th }}$ quantiles) and then increases in the third case ( $75^{\text {th }}$ quantile) (Figure 4).

Table (2) shows that the mean and standard deviation of the estimated $y$ increase in the case of higher quantile (Figure 5, 6).

This proposed model helps in monitoring the changes in $\hat{y}$ over the three quantiles. This can be explored graphically by presenting the $\hat{y}$ surface and $\hat{y}$ chart of the three quantiles. These figures show that $\hat{y}$ is higher in the higher quantile (Figure 7, 8).

All figures and tables in this research are generated by the author. 
Table 1. Proposed Model Results

\begin{tabular}{|c|c|c|c|}
\hline & $25^{\text {th }}$ quantile & $\mathbf{5 0}^{\text {th }}$ quantile & $75^{\text {th }}$ quantile \\
\hline $\mathrm{B}_{0}$ & -17.382 & -17.382 & -17.382 \\
\hline $\mathrm{B}_{1}$ & 11.404 & 25.654 & 28.939 \\
\hline $\mathrm{B}_{2}$ & 0.080 & 0.080 & 0.080 \\
\hline $\mathrm{B}_{3}$ & -0.699 & -0.699 & -0.484 \\
\hline $\mathrm{n}_{1}$ & 63.121 & 43.170 & 36.848 \\
\hline $\mathrm{n}_{2}$ & 14.508 & 1.682 & 0.000 \\
\hline $\mathrm{n}_{3}$ & 32.641 & 0.000 & 0.000 \\
\hline $\mathrm{n}_{4}$ & 9.975 & 0.000 & 0.000 \\
\hline $\mathrm{n}_{5}$ & 45.146 & 8.094 & 0.000 \\
\hline $\mathrm{n}_{6}$ & 0.000 & 0.000 & 0.000 \\
\hline $\mathrm{n}_{7}$ & 29.926 & 0.000 & 0.000 \\
\hline $\mathrm{n}_{8}$ & 7.321 & 0.000 & 0.000 \\
\hline $\mathrm{n}_{9}$ & 54.806 & 14.904 & 2.907 \\
\hline $\mathrm{n}_{10}$ & 0.000 & 0.000 & 0.000 \\
\hline $\mathrm{n}_{11}$ & 0.000 & 0.000 & 0.000 \\
\hline $\mathrm{n}_{12}$ & 31.611 & 7.385 & 0.000 \\
\hline $\mathrm{n}_{13}$ & 277.612 & 0.000 & 0.000 \\
\hline $\mathrm{p}_{1}$ & 0.000 & 0.000 & 0.000 \\
\hline $\mathrm{P}_{2}$ & 0.000 & 0.000 & 3.859 \\
\hline $\mathrm{P}_{3}$ & 0.000 & 0.000 & 0.000 \\
\hline $\mathrm{P}_{4}$ & 0.000 & 0.000 & 7.470 \\
\hline $\mathrm{P}_{5}$ & 0.000 & 0.000 & 2.600 \\
\hline $\mathrm{P}_{6}$ & 10.653 & 27.754 & 35.573 \\
\hline $\mathrm{P}_{7}$ & 0.000 & 0.000 & 8.837 \\
\hline $\mathrm{P}_{8}$ & 0.000 & 8.355 & 0.000 \\
\hline $\mathrm{P}_{9}$ & 0.000 & 0.000 & 0.000 \\
\hline $\mathrm{P}_{10}$ & 0.000 & 22.801 & 28.918 \\
\hline $\mathrm{p}_{11}$ & 58.662 & 31.264 & 43.714 \\
\hline $\mathrm{p}_{12}$ & 0.000 & 0.000 & 3.791 \\
\hline $\mathrm{p}_{13}$ & 0.000 & 0.000 & 4.012 \\
\hline $\mathrm{Z}$ & \multicolumn{3}{|c|}{361.118} \\
\hline
\end{tabular}

Source: table generated by researcher

Table 2. Calculated mean and Standard Deviation of all Estimated Y

\begin{tabular}{|c|c|c|c|}
\hline & $\mathbf{2 5}^{\text {th }}$ quantile & $\mathbf{5 0}^{\text {th }}$ quantile & $\mathbf{7 5}^{\text {th }}$ quantile \\
\hline Mean & 187.7861 & 211.463 & 219.5508 \\
\hline Standard Deviation & 43.29646 & 53.43539 & 55.04773 \\
\hline
\end{tabular}

Source: table generated by researcher 


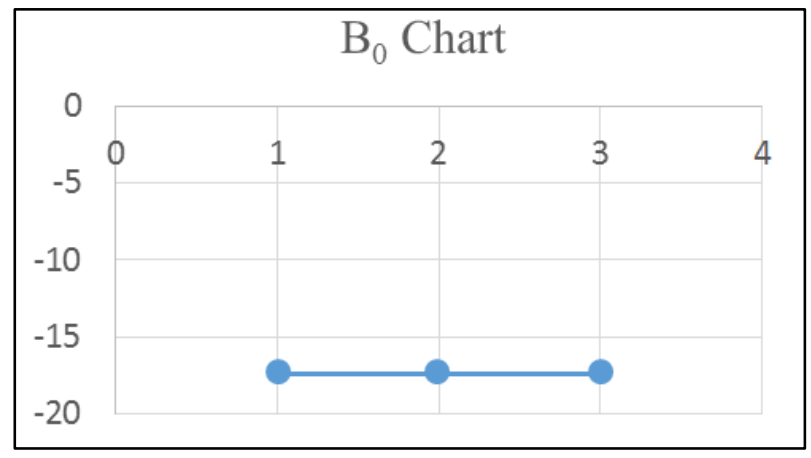

Source: Figure generated by researcher

Figure 1. $\mathrm{B}_{0}$ chart for the three quantiles

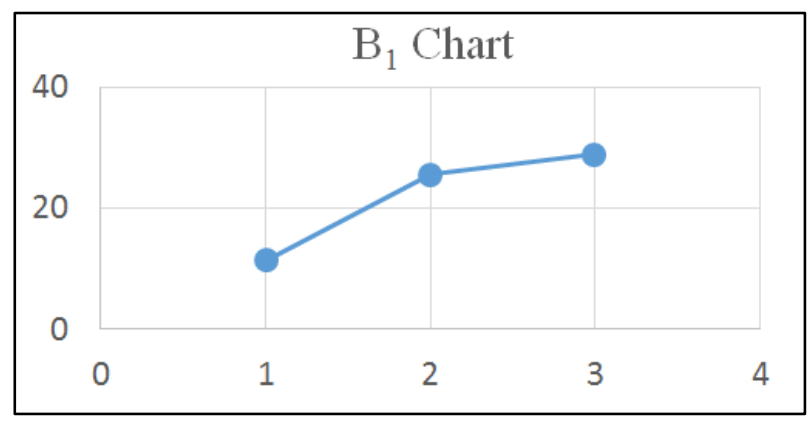

Source: Figure generated by researcher

Figure 2. $B_{1}$ chart for the three quantiles

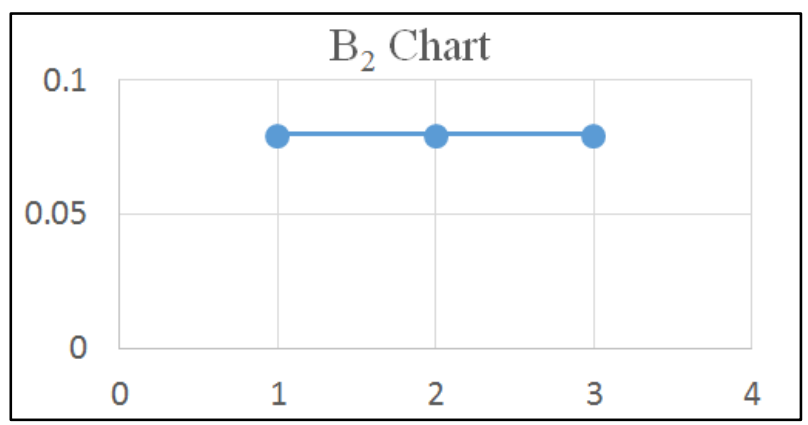

Source: Figure generated by researcher

Figure 3. $B_{2}$ chart for the three quantiles

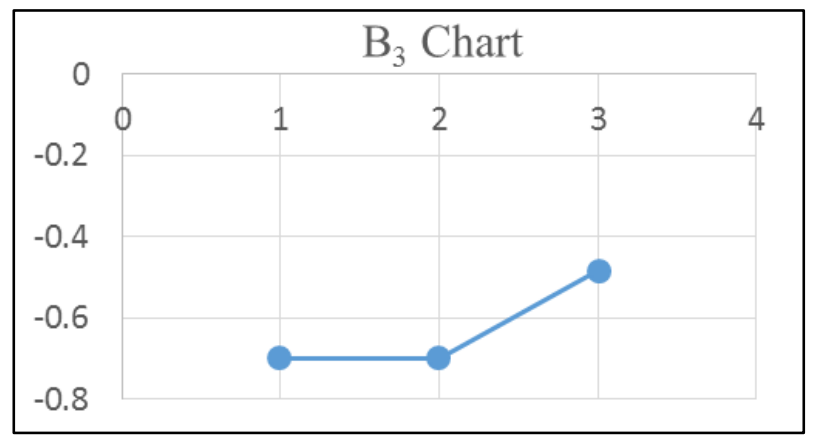

Source: Figure generated by researcher

Figure 4. $B_{3}$ chart for the three quantiles

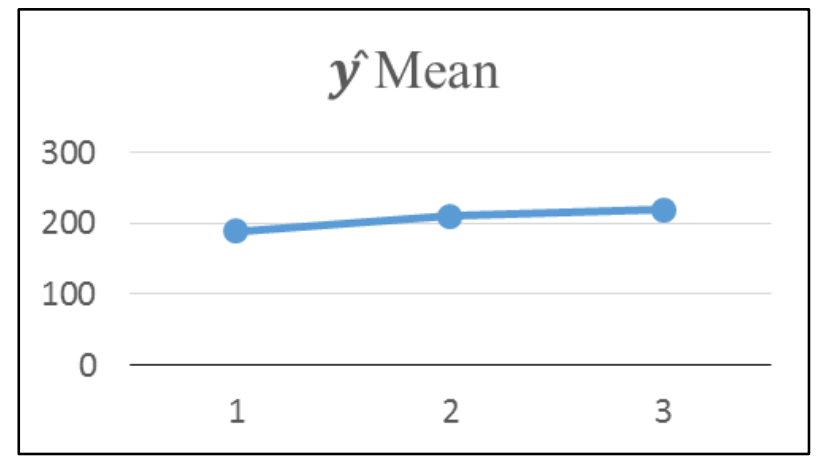

(Source: Figure generated by researcher, i.e. $x$-axis numbers refer to (1) $25 \%$, (2) $50 \%$ and (3) $75 \%$ )

Figure 5. $\hat{\boldsymbol{y}}$ mean for the three quantiles

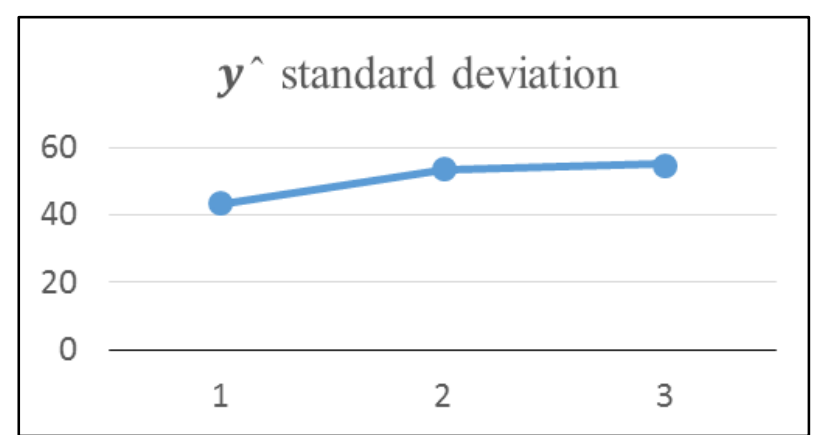

(Source: Figure generated by researcher, i.e. x-axis numbers refer to (1) $25 \%$, (2) $50 \%$ and (3) $75 \%$ )

Figure 6. $\hat{\boldsymbol{y}}$ standard deviation for the three quantiles

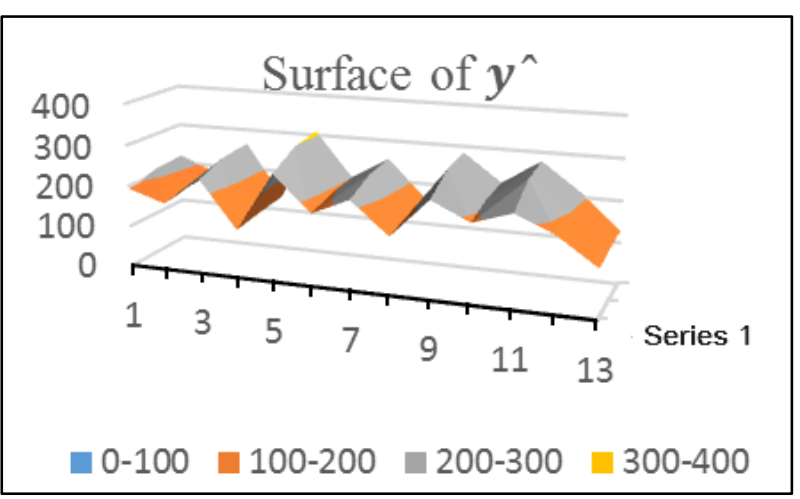

Figure 7. Surface of $\hat{\boldsymbol{y}}$ for the three quantiles

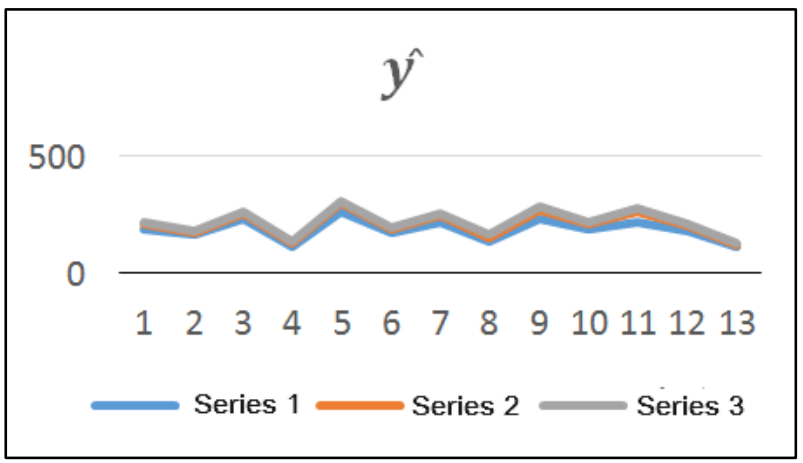

Figure 8. Chart of $\hat{\boldsymbol{y}}$ for the three quantiles 


\section{Simulation Study}

This section presents a simulation study that aims to examine and evaluate the performance of the proposed Goal Programming model by: using generated data from a standard normal distribution; finding an optimal solution by estimating the parameters over different quantiles and minimizing the error using $\mathrm{R}$ software.

Control variables (X's), Dependent Variables (Y) are generated from standard normal distribution as Bilias, Chen and Ying [12] mention. Moreover, 2 and 3 control variables (independent variables) are generated.

Quantiles Tested (q): represented in 25\%, 50\% and 75\% are three levels which are used to evaluate the proposed model performance as in $\mathrm{Yu}, \mathrm{Lu}$ and Stander [9].

The error $(\boldsymbol{\varepsilon})$ is generated from standard normal distribution as mentioned in Bilias, Chen and Ying [12]. Sample size (n): 100 are used.

The number of iteration: 10 and 1000 iteration are used to monitor the change in the results.

Assumed parameters (B's): $b_{0}=5, b_{1}=8, b_{2}=6$ in case of two variables and $b_{0}=5, b_{1}=8, b_{2}=6$ and $b_{3}=4$ in case of three variables.

Table 3 shows the different cases considered in the simulation study; moreover, the remaining tables and graphs, presented in this section, are generated by the author and present the results of A's dataset where the sample size is 100 , and different numbers of variables and iterations were utilized.
Table 3. The Generated Data Details

\begin{tabular}{|c|c|c|c|}
\hline Dataset (\#) & $\begin{array}{c}\text { Sample size } \\
\text { (n) }\end{array}$ & $\begin{array}{c}\text { Number of } \\
\text { variables (\# of } \\
\text { V) }\end{array}$ & $\begin{array}{c}\text { Number of } \\
\text { Iterations (iter) }\end{array}$ \\
\hline $\mathrm{A}_{1}$ & 100 & 2 & 10 \\
\hline $\mathrm{A}_{2}$ & 100 & 2 & 1000 \\
\hline $\mathrm{A}_{3}$ & 100 & 3 & 10 \\
\hline $\mathrm{A}_{4}$ & 100 & 3 & 1000 \\
\hline
\end{tabular}

Source: generated by the researcher.

Table 4 presents the simulation of sample size 100 with 2 variables with different iterations and shows the results of proceeding with the proposed goal programming model concerning the three quantiles $25 \%, 50 \%$, and $75 \%$. It also presents the coefficients estimated by quantile regression to compare between the both estimated results.

Results show that the proposed goal programming model estimated parameters are closed to the parameters estimated from the quantile regression as there is a significant difference between the defined parameters $(5,8$, and 6) and the estimated parameters of both methods.

The error resulting from the proposed model is less than the quantile regression error in all cases where it is close in the $50 \%$ condition (median).

The increase of iterations number helps in decreasing the error, but the bigger difference is in the quantile regression rather than the proposed model.

Table 4. Results of $A_{1}$ and $A_{2}$

\begin{tabular}{|c|c|c|c|c|c|c|c|c|c|c|c|c|}
\hline$\#$ & $\mathbf{N}$ & $\begin{array}{c}\# \text { of } \\
\mathbf{V}\end{array}$ & iter. & $\mathbf{q}$ & & $\begin{array}{l}\text { Iantile } \\
\text { ession's } \\
\text { fficient }\end{array}$ & $\begin{array}{c}\text { B's } \\
\text { changes }\end{array}$ & $\begin{array}{l}\text { Regression } \\
\text { error }\end{array}$ & & $\begin{array}{l}\text { sted Goal } \\
\text { ramming } \\
\text { odels' } \\
\text { fficient }\end{array}$ & $\begin{array}{c}\text { B's } \\
\text { changes }\end{array}$ & $\begin{array}{c}\text { Error } \\
\text { from } \\
\text { modeling }\end{array}$ \\
\hline \multirow{9}{*}{$\mathrm{A}_{1}$} & \multirow{9}{*}{100} & \multirow{9}{*}{2} & \multirow{9}{*}{10} & \multirow{3}{*}{$25 \%$} & $\mathrm{~b}_{0}$ & 4.27119 & 0.7281 & \multirow{3}{*}{39.52575} & $\mathrm{~b}_{0}$ & 4.270992 & 0.72901 & \multirow{3}{*}{30.55212} \\
\hline & & & & & $\mathrm{b}_{1}$ & 7.81686 & 0.18314 & & $\mathrm{~b}_{1}$ & 7.817056 & 0.18294 & \\
\hline & & & & & $\mathrm{b}_{2}$ & 6.02052 & -0.0205 & & $\mathrm{~b}_{2}$ & 6.020946 & -0.0209 & \\
\hline & & & & \multirow{3}{*}{$50 \%$} & $\mathrm{~b}_{0}$ & 4.96143 & 0.0386 & \multirow{3}{*}{40.68336} & $\mathrm{~b}_{0}$ & 4.961407 & 0.03859 & \multirow{3}{*}{40.53123} \\
\hline & & & & & $\mathrm{b}_{1}$ & 7.96041 & 0.03959 & & $\mathrm{~b}_{1}$ & 7.960195 & 0.03981 & \\
\hline & & & & & $\mathrm{b}_{2}$ & 6.12064 & -0.1206 & & $\mathrm{~b}_{2}$ & 6.120706 & -0.1207 & \\
\hline & & & & \multirow{3}{*}{$75 \%$} & $\mathrm{~b}_{0}$ & 5.80792 & -0.8079 & \multirow{3}{*}{41.44221} & $\mathrm{~b}_{0}$ & 5.808135 & -0.8081 & \multirow{3}{*}{31.25707} \\
\hline & & & & & $b_{1}$ & 8.07925 & -0.0793 & & $\mathrm{~b}_{1}$ & 8.0795 & -0.0795 & \\
\hline & & & & & $\mathrm{b}_{2}$ & 6.03064 & -0.0306 & & $\mathrm{~b}_{2}$ & 6.030714 & -0.0307 & \\
\hline \multirow{9}{*}{$\mathrm{A}_{2}$} & \multirow{9}{*}{100} & \multirow{9}{*}{2} & \multirow{9}{*}{1000} & \multirow{3}{*}{$25 \%$} & $\mathrm{~b}_{0}$ & 4.44164 & 0.55836 & \multirow{3}{*}{35.83132} & $\mathrm{~b}_{0}$ & 4.364194 & 0.63581 & \multirow{3}{*}{29.80834} \\
\hline & & & & & $\mathrm{b}_{1}$ & 8.48716 & -0.4872 & & $\mathrm{~b}_{1}$ & 8.414109 & -0.4141 & \\
\hline & & & & & $\mathrm{b}_{2}$ & 5.52431 & 0.47569 & & $\mathrm{~b}_{2}$ & 5.553585 & 0.44642 & \\
\hline & & & & \multirow{3}{*}{$50 \%$} & $\mathrm{~b}_{0}$ & 4.85082 & 0.14918 & \multirow{3}{*}{37.73903} & $\mathrm{~b}_{0}$ & 4.850968 & 0.14903 & \multirow{3}{*}{37.40243} \\
\hline & & & & & $b_{1}$ & 7.88521 & 0.11479 & & $\mathrm{~b}_{1}$ & 7.886762 & 0.11324 & \\
\hline & & & & & $\mathrm{b}_{2}$ & 6.17186 & -0.1719 & & $\mathrm{~b}_{2}$ & 6.171747 & -0.1717 & \\
\hline & & & & \multirow{3}{*}{$75 \%$} & $\mathrm{~b}_{0}$ & 5.61006 & -0.6101 & \multirow{3}{*}{35.23566} & $\mathrm{~b}_{0}$ & 5.60424 & -0.6042 & \multirow{3}{*}{28.52981} \\
\hline & & & & & $\mathrm{b}_{1}$ & 7.98591 & 0.01409 & & $\mathrm{~b}_{1}$ & 8.000362 & -0.0004 & \\
\hline & & & & & $\mathrm{b}_{2}$ & 6.03917 & -0.0392 & & $\mathrm{~b}_{2}$ & 6.031842 & -0.0318 & \\
\hline
\end{tabular}

(Source: table generated by researcher, i.e.: $b_{0}=5, b_{1}=8$ and $b_{2}=6$ are the assumed coefficient) 
Figure 9 shows the graphs of the estimated B's in the case of $A_{1}$ and $A_{2}$. The changes in the estimated parameters are not big while estimated using quantile regression or the proposed model. But, changing the number of iteration affects the estimated coefficient, and this difference between both cases $\left(A_{1}\right.$ and $\left.A_{2}\right)$ is clear in the estimated parameters $\mathrm{b} 1$ and $\mathrm{b} 2$.

Figure 10 clarifies the graphs of quantile regression and proposed goal programming model errors. It shows that the proposed Goal Programming model error is lower, and by increasing the iteration number, the error decreases in both methods. The increase in iteration decreases the error, and it is clearer in quantile regression errors.

Figure 11 shows the mean and standard deviation of estimated $\mathrm{Y}$ over the three quantiles in both cases. The mean of estimated $\mathrm{Y}$, calculated in the case of $\mathrm{A}_{1}$ from quantile regression (2.314773, 2.969411 and 3.791816), is close to the one calculated from a proposed model
$(2.314518,2.969434$ and 3.791972) for the three quantiles, respectively. This is because the standard deviations calculated on case $\mathrm{A}_{1}$ from both methods are close too $(9.613105,9.784028$ and 9.833672) (9.613494, 9.783888, and 9.833917) from quantile regression and proposed model for three quantiles respectively.

By increasing the number of iteration, the mean and standard deviation are closer in both methods: mean (3.173719, 3.623808 and 4.377346), (3.103562, 3.623768 and 4.370156) standard deviation (11.42538, 11.53694 and 11.49314), (11.39354, 11.53817 and 11.49751) from quantile regression and proposed model for three quantiles respectively, but they differ in cases $\mathrm{A}_{1}$ and $\mathrm{A}_{2}$ where they increase by increasing the iteration number.

Moreover, (Figure 12) presented the graphs of estimated $Y$ which seems closer in both methods (quantile regression and proposed model) but differ between cases $A_{1}$ and $A_{2}$.

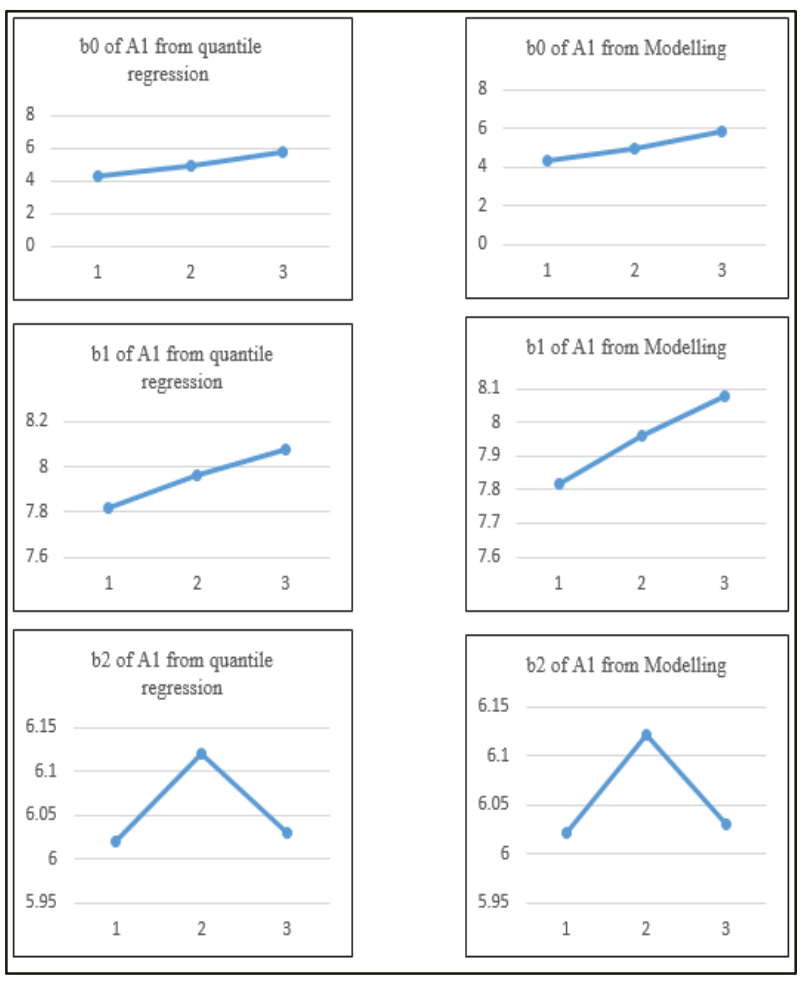

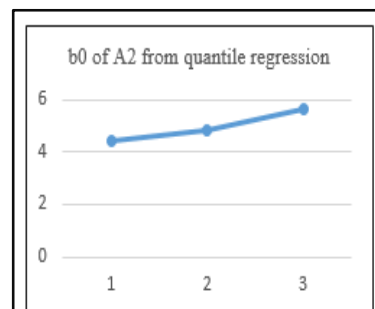
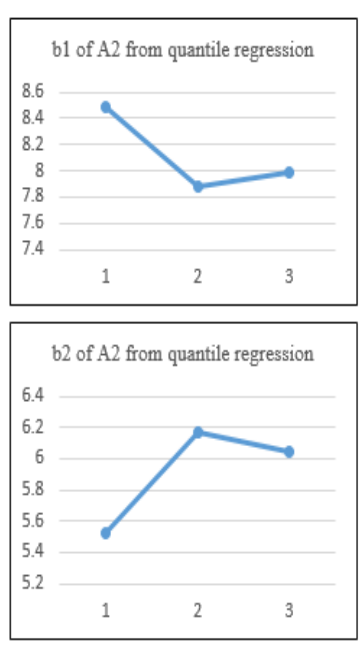
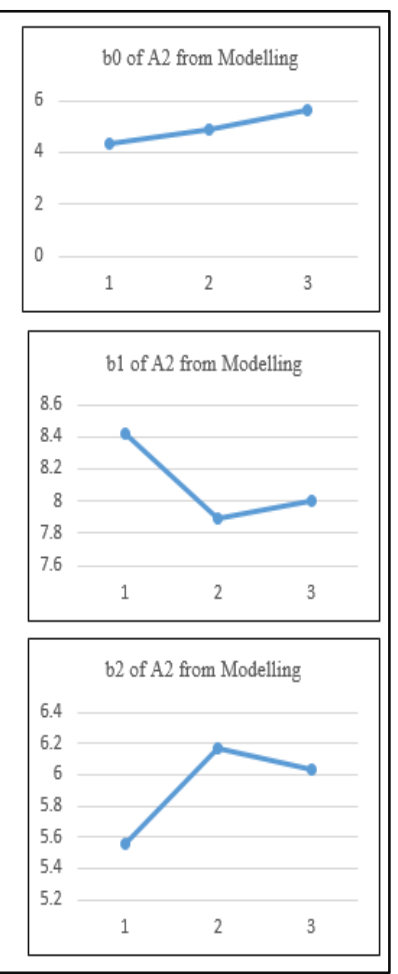

Source: Figure generated by researcher

Figure 9. $\mathrm{A}_{1}, \mathrm{~A}_{2}$ Estimated $\mathrm{B}$ 's of three quantiles 

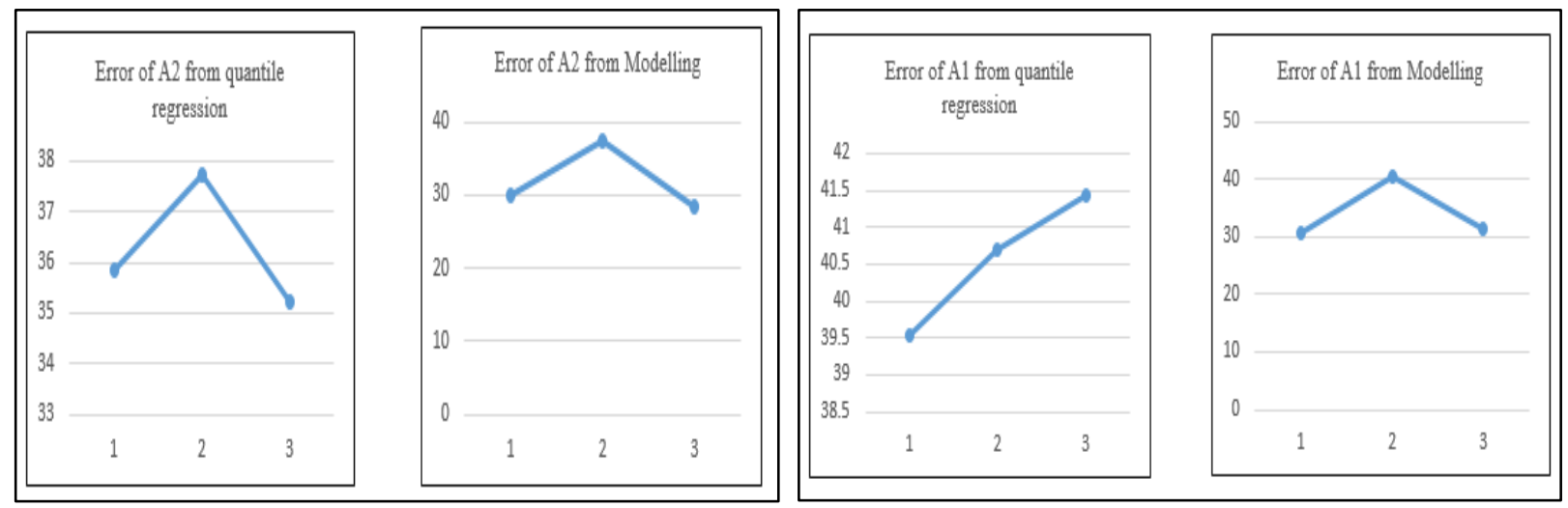

Source: Figure generated by researcher

Figure 10. $A_{1}, A_{2}$ Error of three quantiles

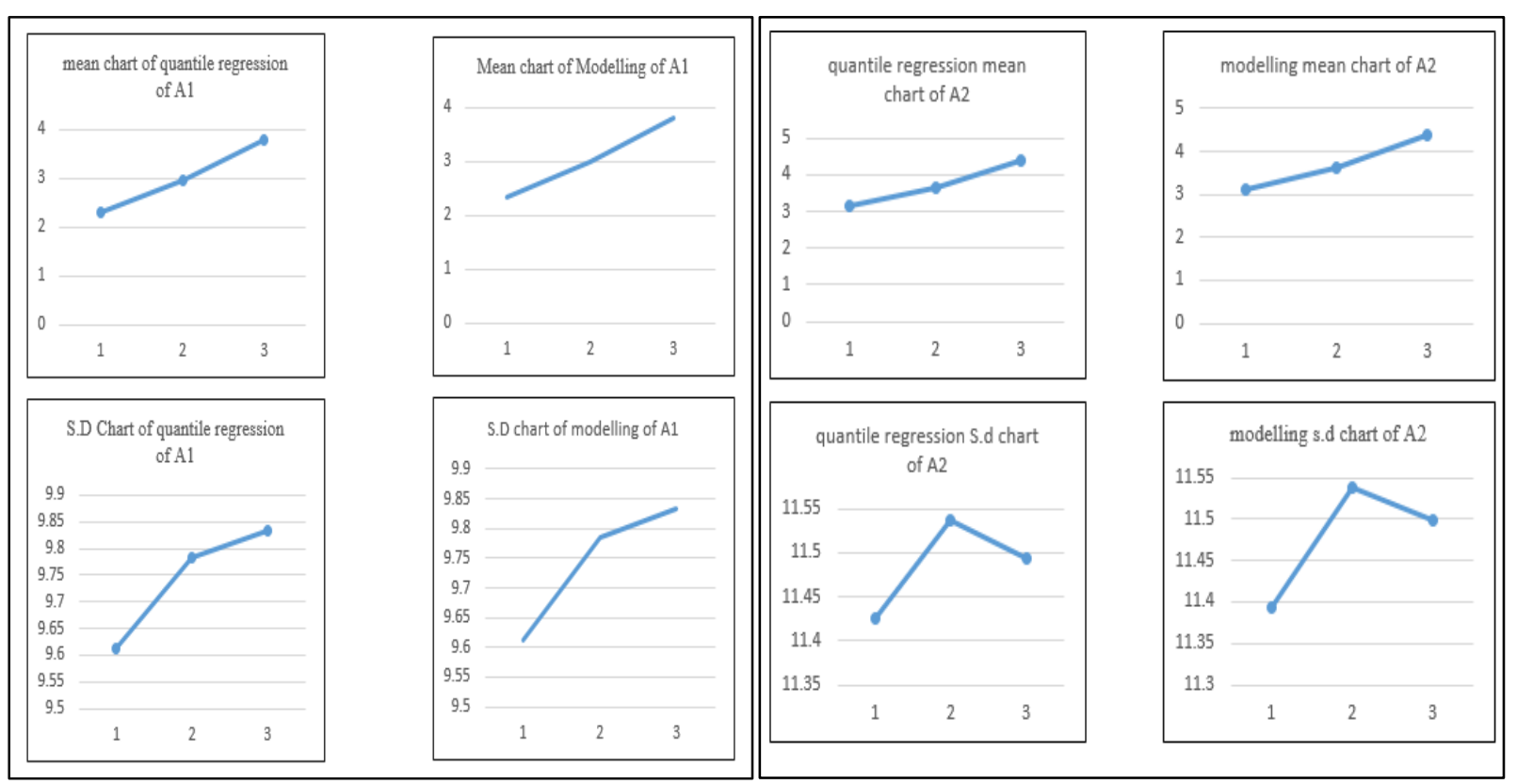

Source: Figure generated by researcher

Figure 11. $A_{1}, A_{2}$ Mean and Standard deviation of Estimated $Y$ of three quantiles 


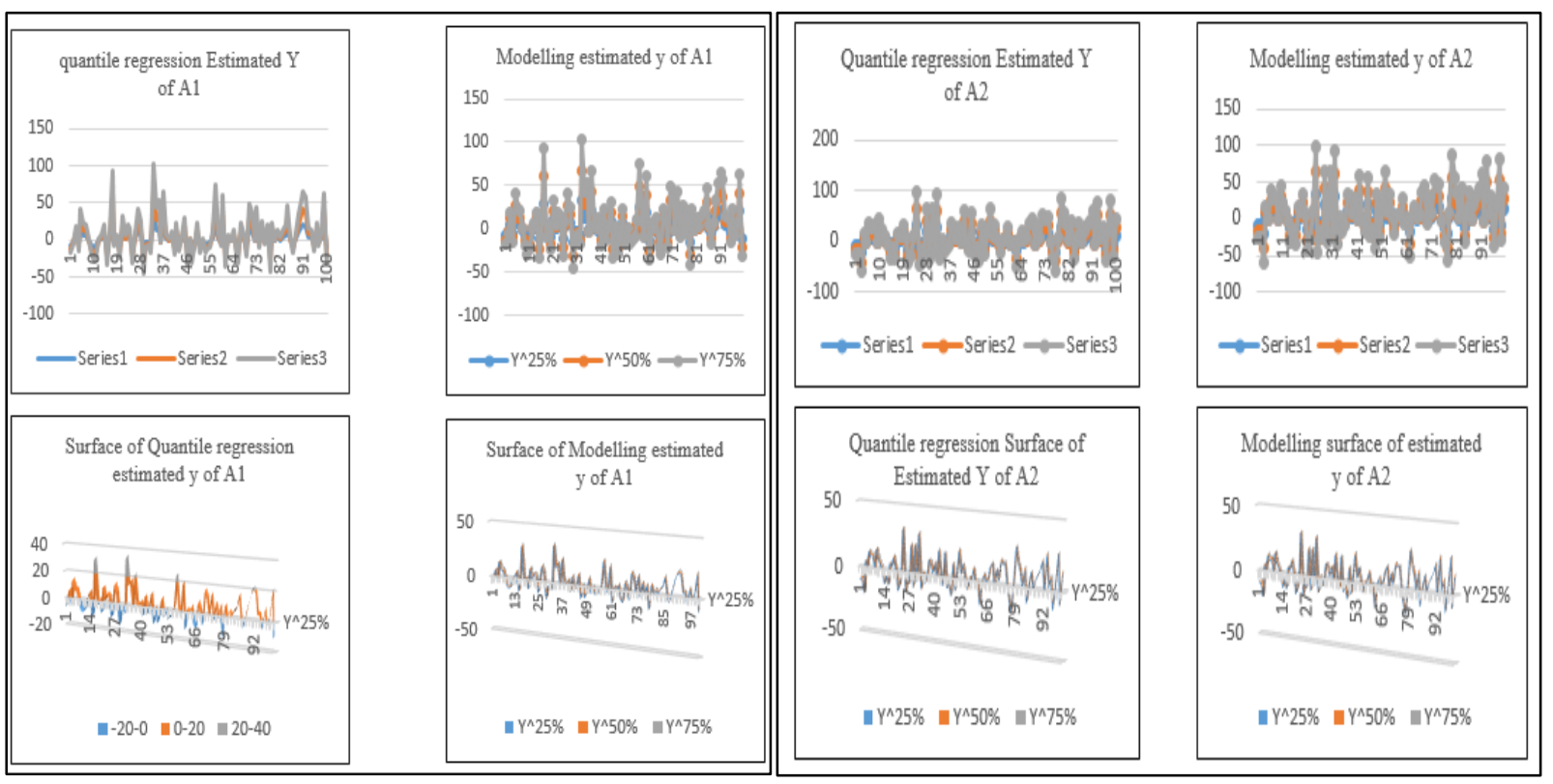

Source: Figure generated by researcher

Figure 12. $A_{1}, A_{2}$ Estimated $Y$ of three quantile

Table 5. Results of $A_{3}$ and $A_{4}$

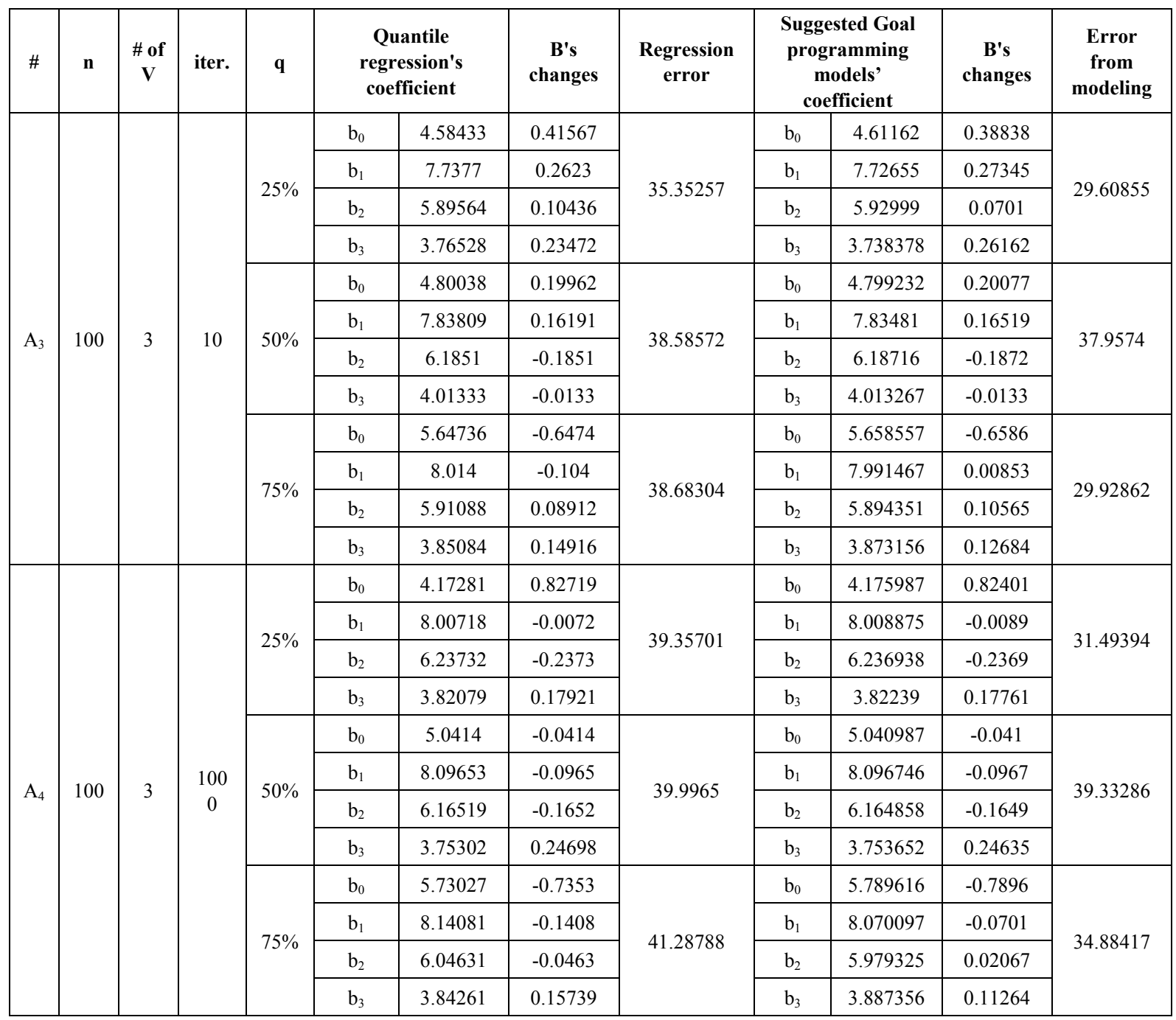

(Source: table generated by researcher, i.e.: $\mathrm{b}_{0}=5, \mathrm{~b}_{1}=8, \mathrm{~b}_{2}=6$ and $\mathrm{b}_{3}=4$ are the assumed coefficient) 
Table 5 shows the data simulated from $\mathrm{R}$ as 3 variables and sample size 100 with different iterations. It shows the results of the three quantiles $25 \%, 50 \%$ and $75 \%$ while using quantile regression and running the proposed model.

The proposed model estimated parameters are close to the parameters estimated from the quantile regression as shown in the above table. There is a difference between the defined coefficient $(5,8,6$, and 4$)$ and the estimated coefficient using both methods.

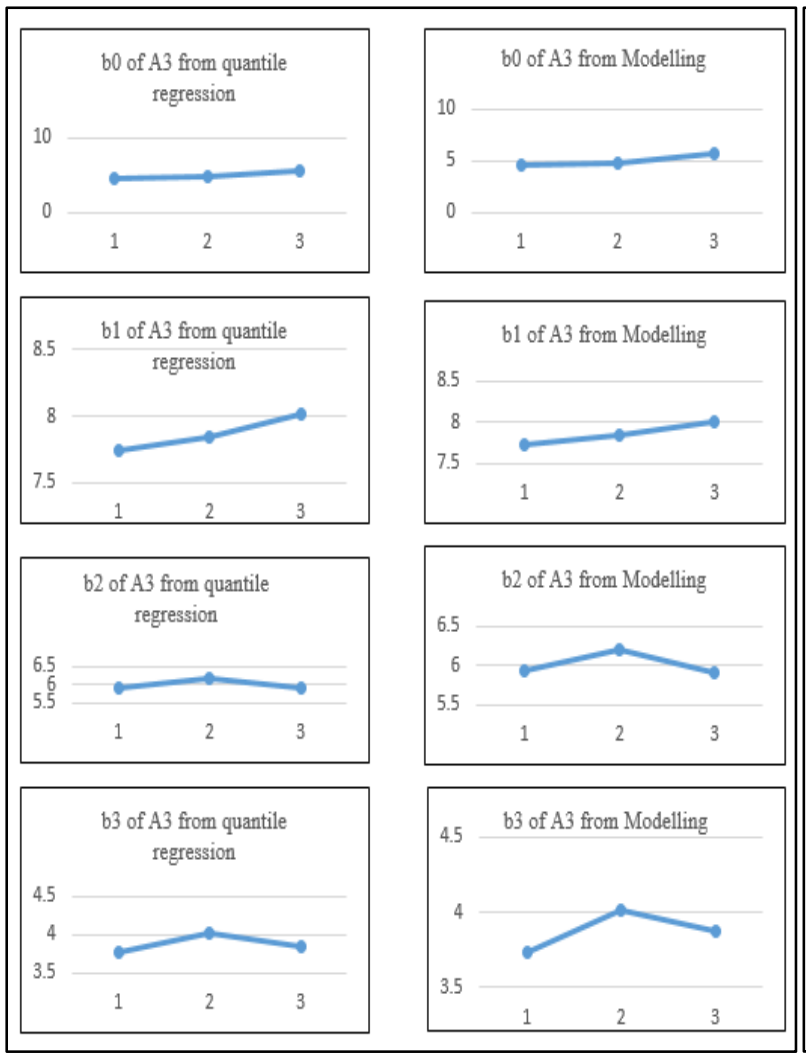

Furthermore, the proposed model error is lower than the quantile regression error in all quantiles except $50 \%$ (median); it is closer. The error decreases by increasing the iterations number, where this difference is clear in the results of quantile regression.

Comparing the four cases $\left(A_{1}, A_{2}, A_{3}\right.$ and $\left.A_{4}\right)$, the increase the iteration and number of variables increases the error where the increase is higher in the quantile regression method.

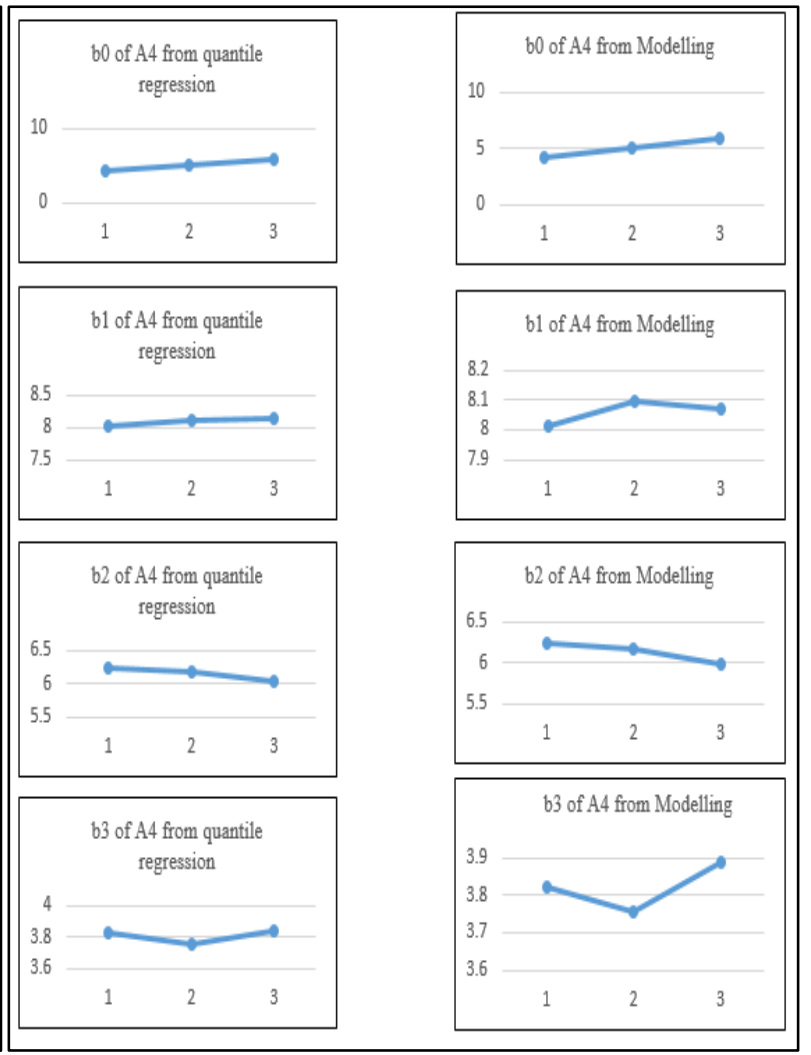

Source: Figure generated by researcher

Figure 13. $\mathrm{A}_{3}$ and $\mathrm{A}_{4}$ Estimated $\mathrm{B}$ 's of three quantiles

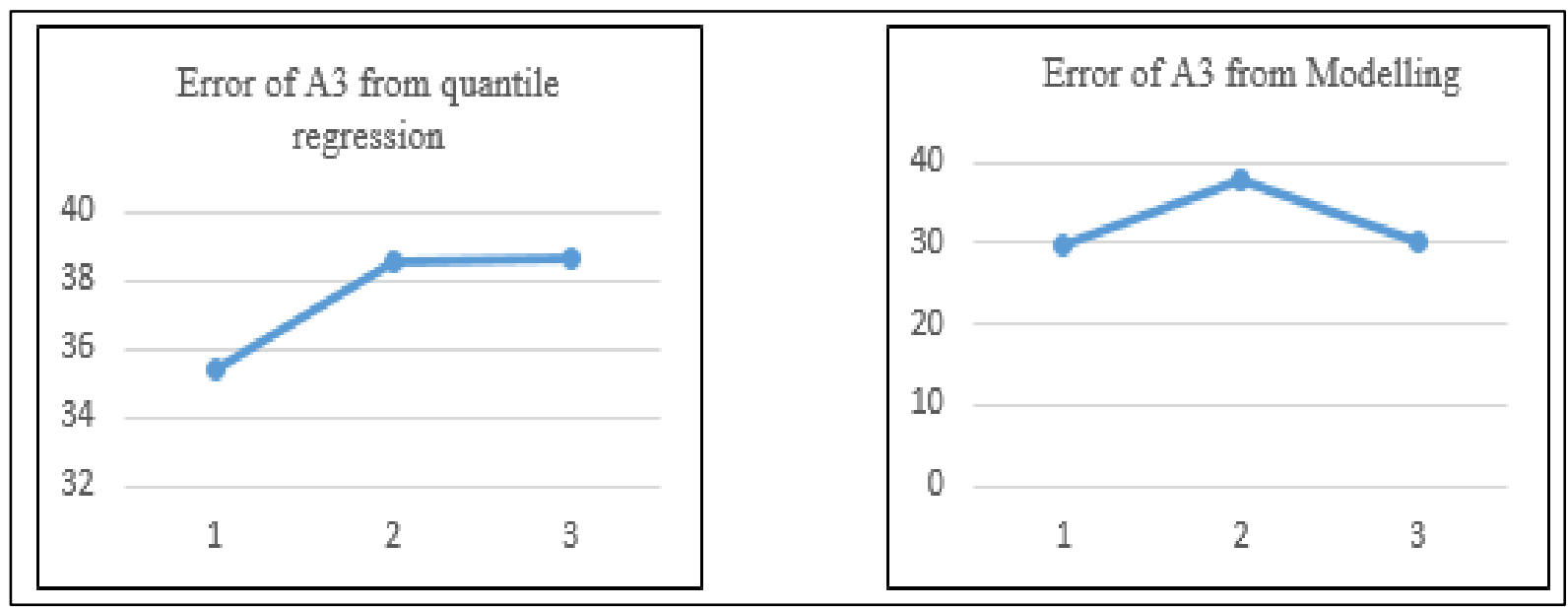

Source: Figure generated by researcher

Figure 14. $\mathrm{A}_{3}$ and $\mathrm{A}_{4}$ Error of three quantiles 
Figure 13 clarifies the graphs of $\mathrm{A}_{3}$ and $\mathrm{A}_{4}$ estimated B's. The estimated coefficient has a big difference between both methods (quantile regression and proposed model). However, the number of iteration increase makes a change in the estimated coefficient between cases $\mathrm{A}_{3}$ and $\mathrm{A}_{4}$.

Figure 14 presents the error graphs of the quantile regression and proposed model. It shows that the proposed model error is lower in both cases $\left(\mathrm{A}_{3}\right.$ and $\left.\mathrm{A}_{4}\right)$. The increase of the iteration number decreases the error of both methods.

Figure 15 shows the calculated mean and standard deviation of the estimated $\mathrm{Y}$ over the three quantile for both cases using the two methods. The mean of estimated $\mathrm{Y}$, calculated in case $\mathrm{A}_{3}$ from quantile regression (5.24133, 5.492843 and 6.355467), is close to the one calculated from proposed model (5.304926, 5.491517 and 6.479226) for the three quantile, respectively.

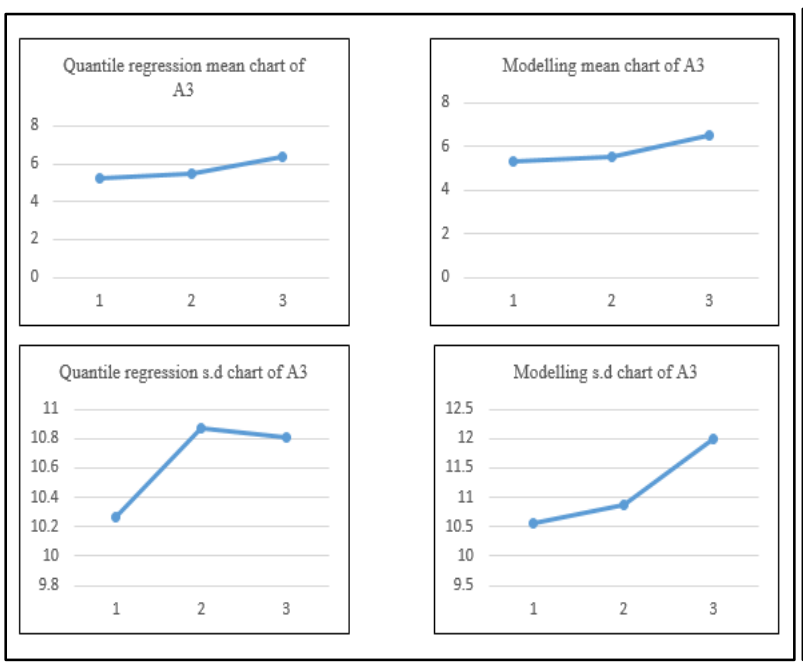

Source: Figure generated by researcher
The standard deviations calculated on case $\mathrm{A}_{3}$ from both methods are close too $(10.26474,10.86874$ and 10.80572), $(10.54616,10.86726$ and 11.99927) from quantile regression and proposed model for three quantiles respectively.

While the number of iteration increases, the mean and standard deviation are closer in both methods; mean (2.955248, 3.816682 and 4.549522), (2.958738, 3.816473 and 4.640588), standard deviation $(12.51837,12.52435$ and 12.54908), (12.52053, 12.5247 and 12.4743) from quantile regression and proposed model for three quantiles respectively, but the standard deviation increases in cases $\mathrm{A}_{4}$.

Figure 16 presents the estimated $\mathrm{Y}$ graphs. The quantile regression graphs are similar to the proposed model graphs, but case $\mathrm{A}_{3}$ graphs are not similar to $\mathrm{A} 4$ graphs.

Figure 15. $\mathrm{A}_{3}$ and $\mathrm{A}_{4}$ Mean and Standard deviation of Estimated $\mathrm{Y}$ of three quantiles
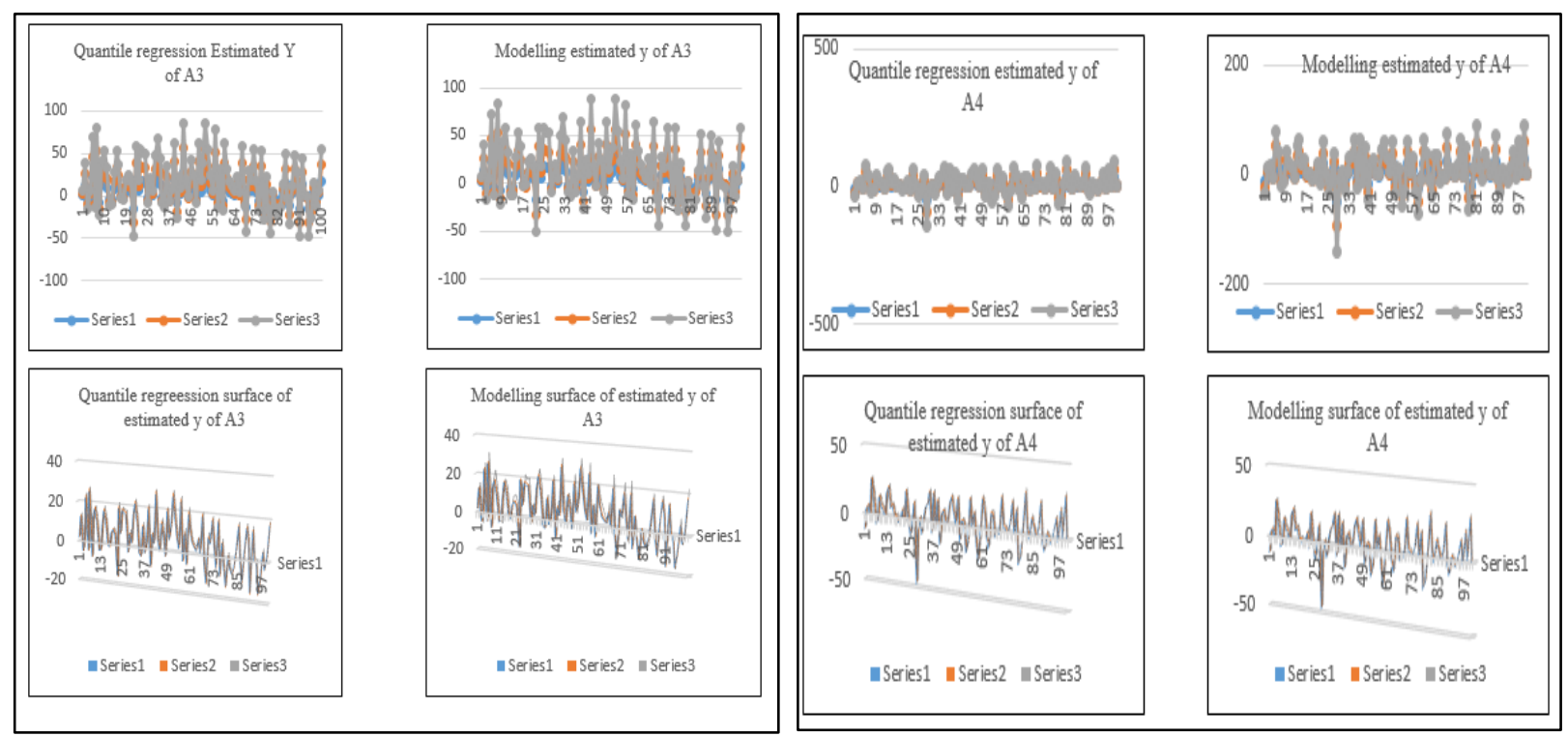

Figure 16. $A_{3}$ and $A_{4}$ Estimated $Y$ of three quantiles 
The conducted simulation study proves the performance of the suggested goal programming model as it shows its quality with increasing the number of independent variables (multi-response). Moreover, it guarantees minimizing the error and having an optimal solution. Besides, the proposed goal programming model which will be useful for the skewed distributions.

\section{Discussion and Conclusions}

This section presents the limitations and main conclusions of this study besides introducing some suggestions for further study.

\subsection{The Study Limitations}

This section presents some of the limitations that the researchers faced through preparing this study:

(1) Prior studies on the same topic: there was a lack of previous studies concerning the same topic. This study represents a merge between experimental design and operation research. All previous studies mentioned in the literature were focusing on helping a certain field or solving a certain problem in the production process. The useof quantile regression and chance constraints together is the new idea proposed in this research.

(2) Data used: finding the data used in previous studies, to evaluate the proposed model, was so difficult. Some studies presented it as codes.

(3) Time: this research takes time to be accomplished as consisting the model and formulating it in chance constraints form, then coding it on the Gams software took a long time to solve errors besides evaluating the model results which required extra time as well.

\subsection{The Main Conclusions}

This section introduces the main results and achievements of this study:

(1) The Proposed model is available for quantitative decision making where its main goal is finding an optimal solution for the available data regardless the shortage of the available resources and information.

(2) Using Goal Programming in the proposed model helps in dealing with a set of objectives besides using the available resources to deal with the goals and their priorities. This is because it is a tool to help the modeling improvement and analyses in real-life cases.

(3) Suggesting the quantile regression to estimate the predictor response helps in understanding relationships between variables regardless the mean of the data. In addition, it may help in dealing with data non-normally distributed which may have nonlinear relationships with the predictor.
(4) The use of the chance-constrained method in the proposed model helps in solving an optimization problem with the problem of uncertainty as it increases the probability of satisfying a certain constraint.

(5) Simulation study helps to prove and evaluate the proposed Goal Programming model performance.

(6) Finally, the proposed Goal Programming model guarantees to work with multiple objectives, many responses while having optimal solutions.

The proposed model can deal with uncertainty problems that exist in real-life applications like production planning, calculating economic growth, logistic services and transportation problem. This is due to its efficiency in finance cases where there is uncertainty in prices like: demand, supply and currency exchange rate. Moreover, it is recommended for optimal renewable energy generation.

\subsection{Suggestions for Further Study}

The following suggestions can be considered for future studies:

(1) Applying the experiment on a wider sample size.

(2) Conducting additional simulation study to compare different sample sizes while using different numbers of variables.

(3) Generating data from different distributions.

(4) Evaluating the model using more quantiles.

(5) Using another statistical package that depends on programming language like $\mathrm{R}$ software.

(6) Organizing a comparative study between the proposed model and old methods.

\section{REFERENCES}

[1] R.H. Myers, and D.C. Montgomery, Response Surface Methodology: Process and Product Optimization using Designed Experiments, Wiley, New York, 1995.

[2] D.C. Montgomery, Design and Analysis of Experiments, Wiley, New York, 2001.

[3] R. Ding, D.K.J. Lin, and D. Wej, Dual- Response Surface Optimization: A Weighted MSE Approach. Quality Engineering, Vol. 16, pp.377-385, 2004.

[4] S. Najafi, A. Salmasnia, and R.B. Kazemezaheh, Optimization of Robust Design for Multiple Response Problem, Australian Journal of Basic and Applied Sciences, Vol. 5, pp.1566-1577, 2011.

[5] R.B. Kazemezadeh, M. Bashiri, A.C. Atkinson, R. Noorossana, A General Framework for Multi Response Optimization Problems based on Goal Programming, Journal of Operational Research, Vol. 189, pp.421-429, 2008.

[6] T.H. Hejazi, M. Bashiri, J.A. Diaz-Garica, and K. Noghondarian, Optimization of Probabilistic Multiple 
Response Surface, Applied Mathematical Modelling, Vol. 36, pp.1275-1285, 2012.

[7] S. Rabee, R.Hamed, R. Kassem, M. Rashwaan, A Goal Programming Approach for Multivariate Calibration Weights Estimation in Stratified Random Sampling, Mathematics and Statistics, Vol.9, No.3, pp.326-334, 2021. DOI: $10.13189 / \mathrm{ms} .2021 .090314$

[8] R.D. Armstrong, and J.H. Balintfy, A Chance Constrained Multiple Choice Programming Algorithm, Operation Research, Vol. 23, No. 3, 1975.

[9] K. Yu, Z. Lu, and J. Stander, Quantile Regression:
Applications and current regression area, Journal of Royal Statistical Society: the Statistician, Vol. 52, pp. 331-350, 2003.

[10] R.N. Rodriguez, and Y. Yao, Five Things You Should Know about Quantile Regression, Paper SAS525, SAS Institute Inc, 2017.

[11] P.S. Mann, Statistical Business and Economics, Johny Wiley \& Sons, 1995.

[12] Y. Bilias, S. Chen, and Z. Ying, Simple resampling methods for censored regression quantiles, Journal of econometrics, Vol.99, No. 2, 373-386, 2000. 